\title{
BMJ Open Conservative care with or without manipulative therapy in the management of back and/or neck pain in Danish children aged 9-15: a randomised controlled trial nested in a school-based cohort
}

Kristina Boe Dissing, ${ }^{1}$ Jan Hartvigsen, ${ }^{1,2}$ Niels Wedderkopp, ${ }^{3,4}$ Lise Hestbæk $^{1,2}$

To cite: Dissing KB, Hartvigsen J, Wedderkopp N, et al. Conservative care with or without manipulative therapy in the management of back and/ or neck pain in Danish children aged 9-15: a randomised controlled trial nested in a school-based cohort. BMJ Open 2018;8:e21358. doi:10.1136/ bmjopen-2017-021358

- Prepublication history and additional material for this paper are available online. To view these files, please visit the journal online (http://dx.doi org/10.1136/bmjopen-2017021358).

Received 3 January 2018 Revised 8 August 2018 Accepted 10 August 2018
D) Check for updates

(c) Author(s) (or their employer(s)) 2018. Re-use permitted under CC BY-NC. No commercial re-use. See rights and permissions. Published by BMJ.

For numbered affiliations see end of article.

Correspondence to Kristina Boe Dissing; kbdissing@health.sdu.dk, kristina@boedissing.dk

\section{ABSTRACT}

Background A substantial number of children experience spinal pain, that is, back and/or neck pain. Today, no 'gold-standard' treatment for spinal pain in children exists, but manipulative therapy is increasingly being used in spite of a lack of evidence of its effectiveness. This study investigates the effectiveness of adding manipulative therapy to other conservative care for spinal pain in a school-based cohort of Danish children aged 9-15 years.

Methods and findings The design was a two-arm pragmatic randomised controlled trial, nested in a longitudinal open cohort study in Danish public schools. 238 children from 13 public schools were randomised individually from February 2012 to April 2014. A text message system and clinical examinations were used for data collection. Interventions included either (1) advice, exercises and soft-tissue treatment or (2) advice, exercises and soft-tissue treatment plus manipulative therapy. The primary outcome was number of recurrences of spinal pain. Secondary outcomes were duration of spinal pain, change in pain intensity and Global Perceived Effect. We found no significant difference between groups in the primary outcome (control group median 1 (IQR 1-3) and intervention group 2 (IQR $0-4), p=0.07$ ). Children in the group receiving manipulative therapy reported a higher Global Perceived Effect: OR 2.22, (95\% Cl 1.19 to 4.15). No adverse events were reported. Main limitations are the potential discrepancy between parental and child reporting and that the study population may not be comparable to a normal care-seeking population.

Conclusions Adding manipulative therapy to other conservative care in school children with spinal pain did not result in fewer recurrent episodes. The choice of treatment-if any-for spinal pain in children therefore relies on personal preferences, and could include conservative care with and without manipulative therapy. Participants in this trial may differ from a normal careseeking population.

Trial registration number NCT01504698; Results.
Strengths and limitations of this study

The school-based design minimised social bias and provided equal access for all.

- The prospective open cohort design allowed for a long follow-up period.

- The text message (SMS) track system is very efficient in collecting frequent data over a long time.

- The SMS track reflects how often parents reported spinal pain on behalf of the child, but this may not reflect the experience of the child.

- The inclusion criteria of a Numerical Rating Scale score of 3 or more on the day of examination and pain for at least 3 days is probably below the normal pain intensity threshold for seeking treatment.

\section{INTRODUCTION}

Spinal pain is common in children and adolescents and prevalence rates reach adult levels already around the age of $18 .{ }^{1}$ For most children, episodes are transient and inconsequential, and therefore, the area has been largely ignored in research. However, some children have frequent, recurrent and bothersome complaints, ${ }^{2-5}$ impacting their mental well-being ${ }^{6}$ and with the potential to decrease the level of physical activity. Importantly, these problems seem to track into adulthood, that is, the most affected adolescents grow up to be the most affected adults. ${ }^{78}$ Therefore, proper management at an early stage is essential to improve lifetime trajectories of spinal pain.

Management of children's musculoskeletal disorders relies to a large extent on parents' values, preferences and experience, and due to absence of guidelines for the treatment of spinal pain in children, healthcare 
professionals have to rely on guidelines developed for adults. $^{9}$

Manipulative therapy (MT) is defined as joint manipulation and/or mobilisation with the aim to restore compromised function of joints. ${ }^{10}$ This type of therapy is increasingly being used in children ${ }^{11-13}$ because it is generally recommended as a treatment option for adults with spinal pain, ${ }^{14-18}$ and is delivered by various health professions, both on its own and in combination with other types of therapy, such as advice, exercises and softtissue treatment. ${ }^{18}$ One study recently demonstrated a small but statistically significant effect of adding MT to exercise therapy ${ }^{19}$ in adolescents with low back pain. However, this is the only full-scale randomised controlled trial (RCT) conducted to date to investigate the effect of SMT in children with any type of spinal pain. ${ }^{90}$

The aim of this pragmatic RCT was to determine the effectiveness of adding MT to other conservative care (advice, exercises and soft-tissue treatment) on the number of recurrences of spinal pain in children aged 9-15 years who were participating in a school-based open cohort study. Secondary outcomes included the shortterm effect on duration of spinal pain episodes, pain intensity and Global Perceived Effect.

\section{METHOD}

\section{Study design}

A pragmatic parallel observer-blinded RCT nested in a school-based open cohort.

\section{Participants and setting}

This study was nested in The Childhood Health, Activity and Motor Performance School Study Denmark (CHAMPS Study-DK), ${ }^{21}$ which is a Danish longitudinal school-based open cohort study including approximately 1400 children aged $9-15$ years from 13 public schools. The CHAMPS Study-DK was an open cohort study hence children could enter or leave the cohort at any time during the study period. The children were followed weekly with text messages (SMS) to one of their parents inquiring, among other things, about any musculoskeletal pain the child might have had during the past week (questions in online supplementary file 1). Data collection on musculoskeletal complaints for this RCT began in February 2012 and ended at the end of June 2014.

\section{Eligibility determination}

All children enrolled in the CHAMPS Study-DK were invited to participate in the RCT. The complete protocol for the RCT is described in detail elsewhere. ${ }^{22}$ Briefly, when a parent answered positively on the SMS to the presence of spinal pain in their child, a member of a screening team (licensed chiropractors and physiotherapists) telephoned the parent and conducted a standardised interview about the complaint, in order to determine whether the child was eligible for inclusion in the RCT. Initial eligibility was based on: (1) the pain was spinal and still present at the time of the interview, (2) the parent had agreed, on behalf of the child, to join the RCT and (3) the child had not had any manual treatment of the spine during the previous 2 months. Within 2 weeks, the child was evaluated at the school by a chiropractor from the RCT team (seven licensed chiropractors) to determine whether he or she fulfilled the inclusion criteria (table 1).

After the evaluation, both the child and his/her parents were informed about the results and treatment was initiated. The flow from SMS to RCT can be seen in figure 1 .

\section{Randomisation}

A computer-generated block randomisation was made with block sizes alternating between two and six at the time of inclusion, using a 1:1 allocation to the two groups. The consecutive designations of the two groups were written on separate pieces of paper and given to the chiropractors in the RCT team in sealed opaque envelopes. A research assistant, who was not otherwise connected to the study, performed the procedure.

\section{First consultation}

At the first consultation, the chiropractor obtained a case history, including pain intensity on an 11-box Numerical Rating Scale, ${ }^{23}$ performed a clinical examination, and various baseline data were acquired (online supplementary file 2). Two weeks after inclusion, the child was asked about Global Perceived Effect (online supplementary file 3) and pain intensity.

If a child experienced a recurrence of pain (ie, the parent-reported pain on the weekly SMS), the procedure was repeated except for randomisation, which was carried forward throughout the study period regardless of the body location in which the complaint occurred. All data were filed in electronic data storage systems

Table 1 Inclusion and exclusion criteria

\begin{tabular}{l|l}
\hline Inclusion criteria & \multicolumn{2}{l}{ Exclusion criteria } \\
\hline $\begin{array}{l}\text { Pain in neck or back equal to or greater than 3 on an 11-box } \\
\begin{array}{l}\text { Numerical Rating Scale for more than 3 days indicated by the } \\
\text { child at the first visit. }\end{array}\end{array}$ & $\begin{array}{l}\text { Serious pathology (cancer, inflammatory diseases, } \\
\text { vertebral fractures, cauda equina syndrome). }\end{array}$ \\
\cline { 2 - 2 } & $\begin{array}{l}\text { Manual treatment for the past 2 months (for this particular } \\
\text { complaint). }\end{array}$ \\
\cline { 2 - 2 } & \begin{tabular}{l} 
Handicaps preventing normal physical activity. \\
\hline
\end{tabular}
\end{tabular}




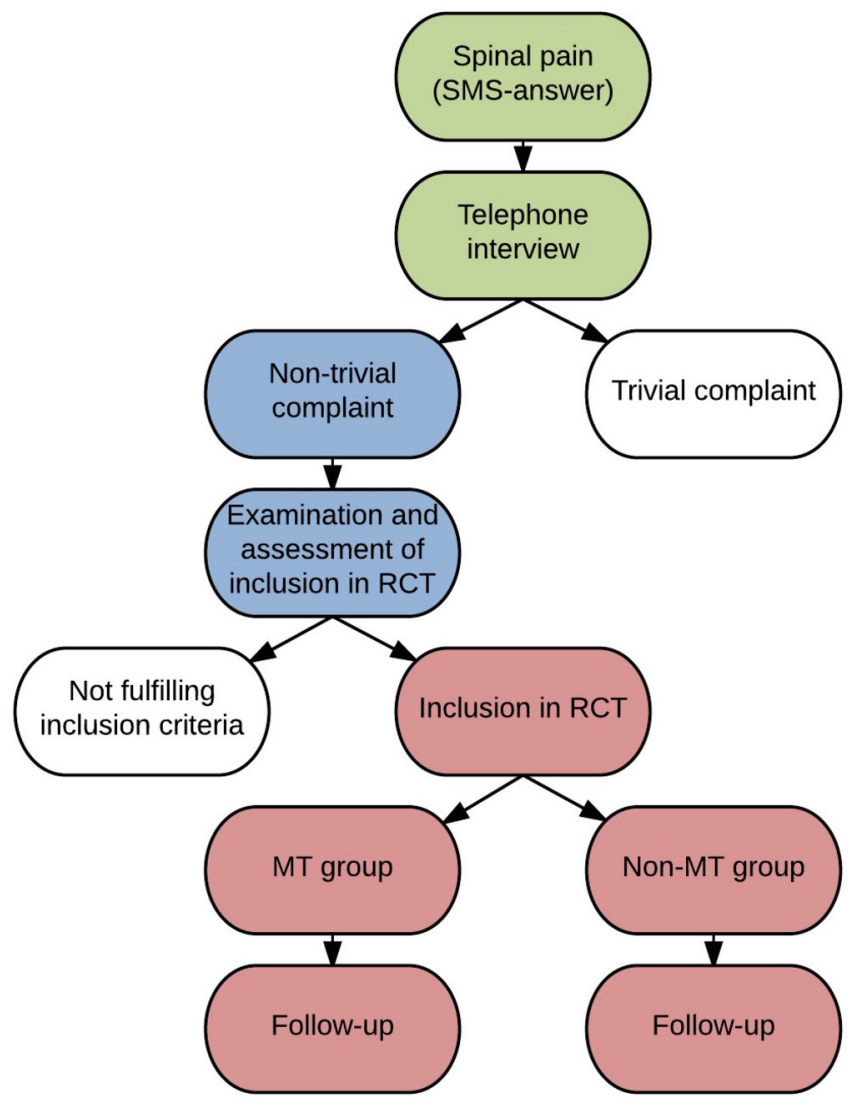

Figure 1 Flow from SMS to RCT. MT group, manipulative therapy group; RCT, randomised controlled trial; SMS, text message.

established specifically for this project and stored on secure servers.

\section{Interventions}

The non-MT group received advice, exercises and softtissue treatment, and the MT group received advice, exercises and soft-tissue treatment plus MT (table 2).

Both groups were treated by the RCT team consisting of seven chiropractors. MT was defined as high velocity, low amplitude manipulation and/or mobilisation of the joints to restore segmental spinal motion. ${ }^{10}$ This was delivered at the discretion of the chiropractor and applied on the basis of a combination of biomechanical dysfunction and pain provocation responses found during the clinical examination of the child, ${ }^{10}$ since palpatory findings by itself have been found unreliable. ${ }^{24}$ If the child experienced any pain in the extremities during the study period, these were also treated with MT at the discretion of the treating chiropractor. Because of the pragmatic nature of the study, the frequency and content of treatments in both groups was determined by the treating chiropractor at each visit, similar to what is normal in clinical practice. Because the RCT team consisted of seven chiropractors, a child could be treated by different chiropractors during different appointments. Treatments continued until the child no longer had any symptoms related to the musculoskeletal complaint, or until the chiropractor or parent decided that further treatment was not indicated. The child and/or parents could terminate the treatments or drop out of the RCT at any time during the study period, but still stay in the cohort of the CHAMPS Study-DK.

\section{Blinding}

Due to the nature of the intervention, blinding of the treating chiropractors was not possible, however, neither parents nor children were informed about group allocation and parents did not attend treatment sessions and answered the SMS without contact with clinicians or researchers. The coding of the intervention group was not revealed to the primary investigator or the statisticians until after the analyses had been completed.

\section{Outcomes}

The primary outcome was the number of recurrences as measured via the weekly SMS messages. A recurrence was defined as a new episode of spinal pain (ie, back and/ or neck pain) occurring after at least 1 week without spinal pain following the end of the previous episode (see secondary outcomes, table 3 ).

\section{Sample size}

As the study had continuous inclusion, we continued to recruit participants until 3 months prior to the end of data collection in summer 2014, to include as many participants as possible with varying follow-up times. Based on preliminary analyses, this resulted in a power of $76 \%$ for the number of recurrences, $20 \%$ for episode length and $87 \%$ for overall complaint time. ${ }^{22}$

\section{Statistical methods}

All analyses used an intention-to-treat approach. Various types of regression analyses were used depending on the type of outcome; follow-up time was included as an exposure time variable; subject was included as random effect in models with repeated measurements; and class and school were evaluated and included in the models as random effects if their effect was statistically significant (see details, table 3). No effect was seen on any of the outcomes and hence, cluster was not included in the models. For linear models, means and SDs were used if data were normally distributed; otherwise medians and

Table 2 Intervention groups

\section{The non-manipulative group}

- Pragmatic advice (activity level, ergonomics, cold packs, etc)

- Exercises (stretching and/or strengthening exercises)

- Soft-tissue treatment (manual trigger point therapy or massage)

\section{The manipulative group received}

- Advice, exercises and soft-tissue treatment

- Manipulative therapy: joint manipulation and/or mobilisation 
Table 3 Outcomes, definitions and statistical methods

\begin{tabular}{|c|c|c|}
\hline & Definition & Statistical method \\
\hline \multicolumn{3}{|l|}{ Primary outcome } \\
\hline $\begin{array}{l}\text { Number of recurrences of spinal pain ( } 3-27 \text { months } \\
\text { follow-up). }\end{array}$ & $\begin{array}{l}\text { (1) A positive answer on the weekly text message for } \\
\text { spinal pain (2) minimum of } 1 \text { week without report of } \\
\text { spinal pain prior to the recurrence. }\end{array}$ & $\begin{array}{l}\text { A hierarchical negative binomial regression model } \\
\text { was used. } \\
\text { Intervention effects were expressed as incidence } \\
\text { rate ratio. }\end{array}$ \\
\hline \multicolumn{3}{|l|}{ Secondary outcomes } \\
\hline Average duration of spinal pain episodes. & $\begin{array}{l}\text { The number of consecutive weeks the child was } \\
\text { affected by spinal pain (response option ' } 1 \text { '). }\end{array}$ & $\begin{array}{l}\text { A mixed-effects linear regression model with subject } \\
\text { as random effect, outcome log transformed was } \\
\text { used. Intervention effects were expressed as the } \\
\text { difference in median length. }\end{array}$ \\
\hline $\begin{array}{l}\text { Total duration of complaint time in relation to } \\
\text { individual follow-up time. }\end{array}$ & $\begin{array}{l}\text { Total number of weeks a child was affected by spinal } \\
\text { pain (response option ' } 1 \text { ') in the entire follow-up } \\
\text { period. }\end{array}$ & $\begin{array}{l}\text { A hierarchical negative binomial regression model } \\
\text { was used. } \\
\text { Intervention effects were expressed as incidence } \\
\text { rate ratio. }\end{array}$ \\
\hline Global Perceived Effect after 2 weeks. & $\begin{array}{l}\text { Dichotomised into two groups: 'Much better' and } \\
\text { 'The same or worse'. }\end{array}$ & $\begin{array}{l}\text { A logistic regression model was used. } \\
\text { Intervention effects were expressed as ORs. }\end{array}$ \\
\hline Change in pain intensity after 2 weeks. & $\begin{array}{l}\text { Rated on an } 11 \text {-point Numerical Rating Scale with '0' } \\
\text { being 'no pain' and ' } 10 \text { ' being 'worst pain'. }\end{array}$ & $\begin{array}{l}\text { A linear regression model was used. } \\
\text { Intervention effects were expressed as the difference } \\
\text { in mean length. }\end{array}$ \\
\hline
\end{tabular}

IQRs were reported. All methods were checked according to fulfilment of other assumptions and changed where appropriate. Due to some missing SMS answers, we imputed missing data as follows: if four or fewer consecutive missing answers were preceded and followed by a ' 1 ', this was considered as one continuous episode and the missing values were imputed as ' $1{ }^{3} .{ }^{3}$ Since this type of outcome measure has not been used in previous trials, there is no consensus on how to substitute data. In a previous article, we have described the consequences of different data substitution strategies. ${ }^{3}$

A sensitivity analysis was conducted to assess the effect of the choice of definitions in relation to recurrence and duration in the present study. In this analysis, a new episode was defined to occur after 4 weeks of 'no pain' instead of 1 week before it was considered a new episode.

STATA V.14.2 (StataCorp) was used for data analyses. Significance level was set to $5 \%$.

A child could be withdrawn from the study at any time during the study period and the study was conducted according to the Declaration of Helsinki.

\section{Patient and public involvement}

There was no patient involvement in the formulation of the research question, the choice of outcome measures, the design, the recruitment procedures, conduct of the study or assessment of the burden of the intervention.

Parents of the included children will receive information about the study and its results via newsletters and the project's website.

\section{RESULTS}

The inclusion period ran from 1 February 2012 to 1 April 2014, and the follow-up period ended on 27 June 2014 (the end of the school year). Follow-up time was defined as 'Number of days between inclusion date and last SMS'. Since one child left the study the day after inclusion, this resulted in 1 to 868 follow-up days, (mean 477 days; SD 233). A total of 770 children reported spinal pain on SMS, and after telephone interviews, 483 children were evaluated for eligibility but did not fulfil the inclusion criteria. Additionally, 44 individuals reported pain less than 3 on the Numerical Rating Scale on the day of examination, leaving 243 children randomised and enrolled in the study. During data cleaning, we found five participants had been wrongly included, that is, the SMS answer indicated no spinal pain, and they were excluded from the analyses. Thus, the final cohort for analysis consisted of 238 children with a mean age of 12.6 years: 116 in the non-MT group (49\%) and 122 in the MT group $(51 \%)$, (see figure 2).

Baseline covariates can be seen in table 4, which also reports the amount of missing data for each variable. There was no difference between the groups for any of the covariates indicating randomisation was successful, and therefore, univariate analyses were performed for all analyses.

\section{Primary outcome}

During the follow-up period, 175 (74\%) of the children had a total of 592 recurrences, ranging from 1 to 21 recurrences per child. The median number of recurrences was 2 (IQR 0-4) for the MT group and 1 (IQR 1-3) for the non-MT group, revealing no statistically significant difference between groups, incidence rate ratio 1.26 (95\% CI 0.98 to 1.61$), \mathrm{p}=0.07$.

\section{Secondary outcomes}

We found no significant difference in the average episode length, total number of pain weeks or change in pain intensity between the two groups. Children in the group receiving MT reported a higher Global Perceived Effect: OR 2.22, (95\% CI 1.19 to 4.15 ), that was statistically significant. All results are displayed in table 5 . 


\section{CONSORT}

TRANSPARENT REPORTING of TRIALS

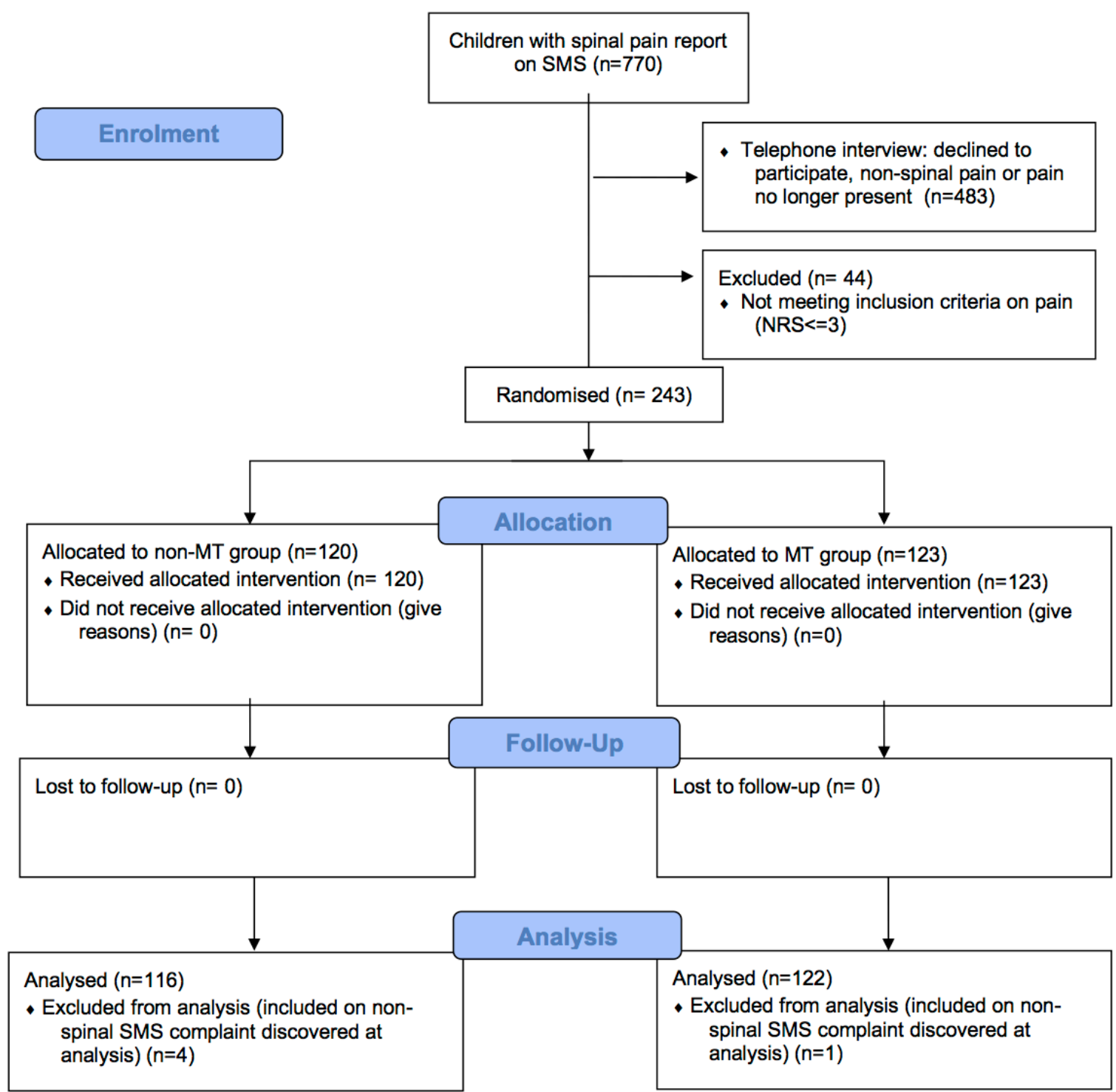

Figure 2 CONSORT flow diagram. CONSORT, Consolidated Standards of Reporting Trials; MT,manipulative therapy; NRS, Numerical Rating Scale; SMS, text message. 
Table 4 Baseline data and covariates by intervention group

\begin{tabular}{|c|c|c|c|c|}
\hline & $\begin{array}{l}\text { Non-MT group } \\
(n=116)\end{array}$ & $\begin{array}{l}\text { MT group } \\
(n=122)\end{array}$ & $\begin{array}{l}\text { Missing non-MT } \\
\text { group* }^{*}\end{array}$ & $\begin{array}{l}\text { Missing MT } \\
\text { group* }\end{array}$ \\
\hline Sex, female, no (\%) & $73(63)$ & $78(64)$ & & \\
\hline Age at inclusion & 12.6 (12.4 to 12.9$)$ & 12.6 (12.3 to 12.9$)$ & & \\
\hline Follow-up time (days) & 492 (448 to 536$)$ & 463 (423 to 504$)$ & & \\
\hline \multirow{2}{*}{$\begin{array}{l}\text { Expectations of the clinical course } \\
\text { ('Worse') }\end{array}$} & $7.6 \%(3.4 \%$ to $16.1 \%)$ & $7.6 \%(3.4 \%$ to $16.1 \%)$ & $32 \%(37)$ & $35 \%(43)$ \\
\hline & Median (IQR) & Median (IQR) & & \\
\hline KID physical well-being & 44.7 (38.5 to 49.6$)$ & 43.8 (40.5 to 49.6$)$ & $4 \%(5)$ & $1 \%(1)$ \\
\hline KID school & 51.1 (45.4 to 58.2$)$ & 51.1 (45.4 to 54.4$)$ & $4 \%(5)$ & $1 \%(1)$ \\
\hline
\end{tabular}

*Number of children with missing data according to intervention group. MT, manipulative therapy; NRS, Numerical Rating Scale.

\section{Table 5 Results on secondary outcomes}

\begin{tabular}{|c|c|c|}
\hline & MT group & Non-MT group \\
\hline \multicolumn{3}{|c|}{ Length of spinal pain episode } \\
\hline Total no of episodes & $456(55 \%)$ & $374(45 \%)$ \\
\hline $\begin{array}{l}\text { Median (IQR) (no of } \\
\text { weeks) }\end{array}$ & $2(1-6)$ & $2(1-5)$ \\
\hline$\beta$-coefficient $(95 \% \mathrm{Cl})$ & \multicolumn{2}{|c|}{$0.11(-0.07$ to 0.29$)$} \\
\hline$P$ value & \multicolumn{2}{|c|}{0.21} \\
\hline \multicolumn{3}{|c|}{ Total duration of complaint time per child } \\
\hline Total no of pain weeks & $1-114$ & $1-111$ \\
\hline Median (IQR) & 9 (IQR 4-22) & 7 (IQR 4-18) \\
\hline $\operatorname{IRR}(95 \% \mathrm{Cl})$ & \multicolumn{2}{|c|}{$1.16(0.92$ to 1.48$)$} \\
\hline$P$ value & \multicolumn{2}{|l|}{0.22} \\
\hline \multicolumn{3}{|l|}{ Global perceived effect } \\
\hline $\begin{array}{l}\text { No of children in } \\
\text { analysis* }\end{array}$ & $96(52 \%)$ & $86(48 \%)$ \\
\hline OR $(95 \% \mathrm{Cl})$ & \multicolumn{2}{|c|}{2.22 (1.19 to 4.15$)$} \\
\hline$P$ value & \multicolumn{2}{|c|}{0.01} \\
\hline \multicolumn{3}{|l|}{ NRS change } \\
\hline $\begin{array}{l}\text { No of children in } \\
\text { analysis* }\end{array}$ & $112(50 \%)$ & $111(50 \%)$ \\
\hline Mean (SD) & $2.2(2.5)$ & $2.3(2.7)$ \\
\hline$\beta$-coefficient $(95 \% \mathrm{Cl})$ & \multicolumn{2}{|c|}{$0.10(-0.57$ to 0.78$)$} \\
\hline$P$ value & \multicolumn{2}{|c|}{0.76} \\
\hline
\end{tabular}

${ }^{*}$ Number of children in analysis of the first episode due to missing data.

IRR, incidence rate ratio; NRS, Numerical rating Scale.

\section{Sensitivity analysis on number of pain free weeks}

The number of recurrences declined from a total of 592 to 259 when we defined a new episode to occur after 4 weeks of 'no pain' instead of 1 week. This, however, did not change the between-group difference on either the primary outcome or most of the secondary outcomes, but it did result in a statistically significant increased length of episode for the MT group, mean 3.5 (3.0-4.0) vs 4.4 weeks (3.8-5.0) and median $2(1-5)$ vs $2(1-4), \mathrm{p}=0.045$.

\section{Harms}

Adverse events can be defined as the sequelae following MT to the spine that are medium to long term in duration, with moderate to severe symptoms, and of a nature that is serious, distressing and unacceptable to the patient and requires further treatment ${ }^{25}$ To our knowledge, no adverse events following MT have been reported in children of this age group ${ }^{2627}$ However, it is common to experience transient side effects such as temporary reddening or soreness in the area being treated after both soft-tissue treatment and $\mathrm{MT}^{28}$ Treating chiropractors recorded transient side effects if the child stated these at the consultation, but none were reported and no child was referred to other healthcare providers, including general practitioners, because of adverse events.

\section{DISCUSSION}

Adding MT to other conservative care for children reporting spinal pain did not result in fewer recurrences in a school-based cohort of Danish children aged 9-15 
years. Furthermore, the average episode length, total number of pain weeks and change in pain intensity were no different between the groups. However, in the sensitivity analyses, filtering out the frequently recurring episodes, the difference for episode length did become statistically significant. Children randomised to the MT group reported a higher Global Perceived Effect that was statistically significant. Thus, no increased effectiveness was evident and no harm was detected.

To our knowledge, this is the first RCT evaluating the added benefit of MT in children with spinal pain (ie, back and/or neck pain). Michaleff $e t a l^{29}$ found only four RCTs dealing with conservative interventions for low back pain in children and all had a high risk of bias. Only one of these included manual therapy combined with exercise, but it had only 45 participants.

Because this study was a two-armed parallel trial with MT as an addition to other conservative care, it is probably not surprising that we did not find a large difference between the two groups. This RCT was nested in a large cohort study, and hence we could not prolong the study period to increase the sample size; however, given the small absolute differences found on both primary and secondary outcomes, this is unlikely to have changed our conclusions.

\section{Choice of outcomes}

We originally intended to analyse the three spinal regions separately, however, the pain site could change within the same individual during follow-up, and many individuals reported pain from several regions. Therefore, the interpretation of our results relate to 'spinal pain' as a coherent entity. We could not determine by the SMS answers whether recurrences were actual recurrences of the same problem at the same location in the spine, but simply conclude that there was subsequent spine-related pain. This can be considered a weakness as we cannot determine true recurrences; however, it can also be considered to be a strength because pain in this age group appears to demonstrate a shift between regions of the spine over time, indicating that there is not independence between pain in the three regions. ${ }^{2}$

The Numerical Rating Scale has been shown to be a valid tool for assessing pain in children, ${ }^{23} 3031$ and in this study, the children also appeared to be able to rate their pain on the scale quite easily. However, when analysing the data, we found that Numerical Rating Scale ratings were not always in accordance with Global Perceived Effect ratings, that is, some children would say they felt better, although reporting a higher score on the Numerical Rating Scale at follow-up than at baseline. This noise may be caused by variation in cognitive abilities and maturity between the children, and is probably equally distributed between groups. Regardless, we did not find statistically significant differences between the groups on change in Numerical Rating Scale scores, and both achieved a mean change of 2.3, which can be regarded as a clinically meaningful change, as studies have shown a minimal clinically important change to be $\pm 1 .{ }^{32} 33$

We could not find any literature supporting the validity of measures of Global Perceived Effect in children, but validity of this measure has been shown to be good in adults $^{3435}$ and we therefore included it as a measure of the child's own perception of improvement. We would have expected that statistically significant differences between the groups would follow the same pattern for the Numerical Rating Scale and the Global Perceived Effect, but this was not the case. Therefore, the validity of both of these as outcome measures in clinical trials involving children should be further explored.

\section{Strengths and weaknesses}

The principal strength of this study was the school-based design, which had a number of advantages: the logistical burden for the parents was reduced because the treatment took place during school time, social bias was likely to be minimal or absent because everybody was invited to participate in the study, and there was equal access because all treatment in the trial was free. Also, this design allowed for a long follow-up period for most children. By nesting this RCT in a school-based cohort, we may however have included children who would not normally have sought care, that is, likely to have had subclinical pain. The inclusion criterion of a Numerical Rating Scale score of 3 or more on the day of examination is probably also below the normal pain intensity threshold for seeking treatment and many parents would probably have waited until the pain had become worse or lasted longer before seeking care. On the other hand, the number and duration of spinal pain episodes were higher in the study sample than in the full cohort (mean number 3.5 vs 2 , mean duration 4.6 vs 2.8), ${ }^{36}$ suggesting that the children enrolled in this study were more affected by pain than their non-participating peers.

SMS is a very efficient way of collecting frequent data over a long time. ${ }^{3738}$ In this study, the SMS responses were a reflection of how often the parents reported on their child's pain and might not have been a true reflection of how the child actually felt. We know that there is a discrepancy between parent and child reporting of spinal pain. ${ }^{39-41}$ Parents appear to under-report compared with their child when pain is at a low level, whereas concordance is higher when the pain is more severe. Thus, it is possible that the parents stopped reporting pain because they assumed the complaint to be minor, even though the child might still have had pain. This could explain some of the difference between outcomes reported by the children (Global Perceived Effect) and outcome reported by the parents (SMS).

Using different practitioners prevents a potential patient-practitioner relationship and is considered a strength; however, the more people involved, the more irregularities and mistakes are likely to occur. One example of this is the poor response rate to the measures 
collected by the clinicians, for example, Numerical Rating Scale and Global Perceived Effect scores.

\section{Missing data}

The amount of missing data was substantial for some of the secondary outcomes, and therefore, we analysed only those for the first spinal pain episode. However, there was no difference in response rates between groups, and it was assumed that data were missing completely at random and not due to any underlying confounding factors or bias. Possible reasons for missing data could be practitioners' forgetfulness or an electronic system defect resulting in missing data. Because of missing data, we cannot say anything valid about the course of pain, for example, whether there is a learning effect over time or whether expectations of treatment differ over time between the two groups.

\section{Future research}

Since the inclusion criteria in this study were very broad, subgroup analyses would be valuable to inform future studies, that is, if there are subgroups of children who respond better or worse to MT than to other treatments. Future RCTs should include care-seeking children who self-report their response to treatment in order to evaluate effectiveness in that population. In addition, inclusion of an untreated group would elucidate the effect of treating these children, whether MT is included or not.

\section{CONCLUSION}

We found no significant difference in the number of recurrences of episodes of spinal pain in a school-based cohort of children when adding MT to advice, exercises and soft-tissue therapy. The study population may not be comparable to a normal care-seeking population, and therefore, the results may not be directly transferrable.

\section{Author affiliations \\ ${ }^{1}$ Department of Sports Science and Clinical Biomechanics, Faculty of Health Sciences, University of Southern Denmark, Odense, Denmark \\ ${ }^{2}$ Nordic Institute of Chiropractic and Clinical Biomechanics, Odense, Denmark ${ }^{3}$ Institute of Regional Health Services Research, University of Southern Denmark, Odense, Denmark \\ ${ }^{4}$ Sports Medicine Clinic, Orthopaedic Department Hospital of Lillebaelt, Østre Hougvej, Middelfart, Denmark}

Acknowledgements The authors gratefully acknowledge the Nordic Institute of Chiropractic and Clinical Biomechanics for providing office space and support. Furthermore, we would like to thank Suzanne Capell for proof reading the manuscript. Finally, we would like to thank the participants and their parents and the participating schools, and Werner Vach and Eleanor Boyle for advice in matters relating to sample size calculations and description of the analysis. In addition, we acknowledge all the members of the CHAMPS Study-DK and the clinicians taking part in this study for making it possible.

Contributors All authors (KBD, JH, NW and $\mathrm{LH}$ ) participated in the design and interpretation of analyses of this study. KBD was project manager for the trial and drafted the manuscript. All authors (KBD, JH, NW and $\mathrm{LH}$ ) contributed with revisions and approved the final version of the manuscript.

Funding This work was supported by The IMK Foundation, The Danish Chiropractic Research Foundation, The Nordea Foundation and The TRYG Foundation, who funded the data collection as well as salaries and equipment for examination and treatment of the children in the RCT. The salary of the first author (KBD) was funded by the Danish Chiropractic Research Foundation and the University of Southern Denmark, in order to complete this project. The other authors did not receive specific grants for this study.

Disclaimer The funders had no role in the study design, data analysis, decision to publish or preparation of this paper.

Competing interests None declared.

Patient consent Not required.

Ethics approval The project was approved by The Regional Committee on Health Research Ethics (\#S-20110042) and data were handled according to the regulations set by the Danish Data Protection Agency (\#2013-41-1738).

Provenance and peer review Not commissioned; externally peer reviewed.

Data sharing statement Data are from the Childhood Health, Activity and Motor Performance School Study (CHAMPS Study-DK) and are available on request from the project manager Niels Wedderkopp.

Open access This is an open access article distributed in accordance with the Creative Commons Attribution Non Commercial (CC BY-NC 4.0) license, which permits others to distribute, remix, adapt, build upon this work non-commercially, and license their derivative works on different terms, provided the original work is properly cited, appropriate credit is given, any changes made indicated, and the use is non-commercial. See: http://creativecommons.org/licenses/by-nc/4.0/.

\section{REFERENCES}

1. Leboeuf-Yde C, Kyvik KO. At what age does low back pain become a common problem? A study of 29,424 individuals aged 12-41 years. Spine 1998;23:228-34.

2. Aartun E, Hartvigsen J, Wedderkopp N, et al. Spinal pain in adolescents: prevalence, incidence, and course: a school-based two-year prospective cohort study in 1,300 Danes aged 11-13. BMC Musculoskelet Disord 2014;15:187.

3. Dissing KB, Hestbæk L, Hartvigsen J, et al. Spinal pain in Danish school children - how often and how long? The CHAMPS Study-DK. BMC Musculoskelet Disord 2017;18:67.

4. Kamper SJ, Henschke N, Hestbaek L, et al. Musculoskeletal pain in children and adolescents. Braz J Phys Ther 2016;20:275-84.

5. Taimela S, Kujala UM, Salminen JJ, et al. The prevalence of low back pain among children and adolescents. A nationwide, cohort-based questionnaire survey in Finland. Spine 1997;22:1132-6.

6. Stallknecht SE, Strandberg-Larsen K, Hestbæk L, et al. Spinal pain and co-occurrence with stress and general well-being among young adolescents: a study within the Danish National Birth Cohort. Eur J Pediatr 2017;176:807-14.

7. Brattberg G. Do pain problems in young school children persist into early adulthood? A 13-year follow-up. Eur J Pain 2004;8:187-99.

8. Hestbaek L, Leboeuf-Yde C, Kyvik KO, et al. The course of low back pain from adolescence to adulthood: eight-year follow-up of 9600 twins. Spine 2006;31:468-72.

9. Hestbaek L, Stochkendahl MJ. The evidence base for chiropractic treatment of musculoskeletal conditions in children and adolescents: The emperor's new suit? Chiropr Osteopat 2010;18:15.

10. Thomas F, Bergmann DHP. Chiropractic Technique. Principles and Procedures. 3rd ed. Missouri: United States of America: Elsevier Mosby, 2011:35-74.

11. Black LI, Clarke TC, Barnes PM, et al. Use of complementary health approaches among children aged 4-17 years in the United States: National Health Interview Survey, 2007-2012. Natl Health Stat Report 2015;78:1-19.

12. Ndetan H, Evans MW, Hawk C, et al. Chiropractic or osteopathic manipulation for children in the United States: an analysis of data from the 2007 National Health Interview Survey. J Altern Complement Med 2012;18:347-53.

13. Hurwitz EL. Epidemiology: spinal manipulation utilization. $J$ Electromyogr Kinesiol 2012;22:648-54.

14. Bronfort G, Haas M, Evans R, et al. Effectiveness of manual therapies: the UK evidence report. Chiropr Osteopat 2010;18:3.

15. Goertz CM, Long CR, Hondras MA, et al. Adding chiropractic manipulative therapy to standard medical care for patients with acute low back pain: results of a pragmatic randomized comparative effectiveness study. Spine 2013;38:627-34.

16. Wong JJ, Côté P, Sutton DA, et al. Clinical practice guidelines for the noninvasive management of low back pain: A systematic review by the Ontario Protocol for Traffic Injury Management (OPTIMa) Collaboration. Eur J Pain 2017;21:201-16. 
17. Stochkendahl MJ, Kjaer P, Hartvigsen J, et al. National Clinical Guidelines for non-surgical treatment of patients with recent onset low back pain or lumbar radiculopathy. Eur Spine J 2018;27.

18. Koes BW, van Tulder M, Lin CW, et al. An updated overview of clinical guidelines for the management of non-specific low back pain in primary care. Eur Spine J 2010;19:2075-94.

19. Evans R, Haas M, Schulz C, et al. Spinal manipulation and exercise for low back pain in adolescents: a randomized trial. Pain 2018;159:1297-307.

20. Gleberzon BJ, Arts J, Mei A, et al. The use of spinal manipulative therapy for pediatric health conditions: a systematic review of the literature. J Can Chiropr Assoc 2012;56:128-41.

21. Wedderkopp N, Jespersen E, Franz C, et al. Study protocol. The Childhood Health, Activity, and Motor Performance School Study Denmark (The CHAMPS-study DK). BMC Pediatr 2012;12:128.

22. Dissing KB, Hartvigsen J, Wedderkopp N, et al. Conservative care with or without manipulative therapy in the management of back and neck pain in Danish children aged 9-15. Study protocol for a randomized controlled trial. Chiropr Man Therap 2016;24:5.

23. von Baeyer CL, Spagrud LJ, McCormick JC, et al. Three new datasets supporting use of the Numerical Rating Scale (NRS-11) for children's self-reports of pain intensity. Pain 2009;143:223-7.

24. Stochkendahl MJ, Christensen HW, Hartvigsen J, et al. Manual examination of the spine: a systematic critical literature review of reproducibility. J Manipulative Physiol Ther 2006;29:475-85.

25. Puentedura EJ, O'Grady WH. Safety of thrust joint manipulation in the thoracic spine: a systematic review. J Man Manip Ther 2015;23:154-61.

26. Todd AJ, Carroll MT, Robinson A, et al. Adverse Events Due to Chiropractic and Other Manual Therapies for Infants and Children: A Review of the Literature. J Manipulative Physiol Ther 2015;38.

27. Jevne J, Hartvigsen J, Christensen HW. Compensation claims for chiropractic in Denmark and Norway 2004-2012. Chiropr Man Therap 2014;22:37.

28. Paanalahti K, Holm LW, Nordin M, et al. Adverse events after manual therapy among patients seeking care for neck and/or back pain: a randomized controlled trial. BMC Musculoskelet Disord 2014;15:77.

29. Michaleff ZA, Kamper SJ, Maher CG, et al. Low back pain in children and adolescents: a systematic review and meta-analysis evaluating the effectiveness of conservative interventions. Eur Spine $J$ 2014;23:2046-58.

30. Miró J, Castarlenas E, Huguet A. Evidence for the use of a numerical rating scale to assess the intensity of pediatric pain. Eur $J$ Pain 2009:13:1089-95.

31. Castarlenas E, Miró J, Sánchez-Rodríguez E. Is the verbal numerical rating scale a valid tool for assessing pain intensity in children below 8 years of age? J Pain 2013;14:297-304.

32. Salaffi F, Stancati A, Silvestri CA, et al. Minimal clinically important changes in chronic musculoskeletal pain intensity measured on a numerical rating scale. Eur J Pain 2004;8:283-91.

33. Voepel-Lewis $\mathrm{T}$, Burke $\mathrm{CN}$, Jeffreys $\mathrm{N}$, et al. Do 0-10 numeric rating scores translate into clinically meaningful pain measures for children? Anesth Analg 2011;112:415-21.

34. Kamper SJ, Ostelo RW, Knol DL, et al. Global Perceived Effect scales provided reliable assessments of health transition in people with musculoskeletal disorders, but ratings are strongly influenced by current status. J Clin Epidemiol 2010;63:760-6.

35. Evans R, Bronfort G, Maiers M, et al. "I know it's changed": a mixedmethods study of the meaning of Global Perceived Effect in chronic neck pain patients. Eur Spine J 2014;23:888-97.

36. Dissing KB, Hestbæk L, Hartvigsen J, et al. Spinal pain in Danish school children - how often and how long? The CHAMPS Study-DK. BMC Musculoskelet Disord 2017;18:67.

37. Axén I, Bodin L, Bergström G, et al. The use of weekly text messaging over 6 months was a feasible method for monitoring the clinical course of low back pain in patients seeking chiropractic care. J Clin Epidemiol 2012;65:454-61.

38. Johansen B, Wedderkopp N. Comparison between data obtained through real-time data capture by SMS and a retrospective telephone interview. Chiropr Osteopat 2010;18:10.

39. Kamper SJ, Dissing KB, Hestbaek L. Whose pain is it anyway? Comparability of pain reports from children and their parents. Chiropr Man Therap 2016:24:24:24.

40. Sundblad GM, Saartok T, Engström LM. Child-parent agreement on reports of disease, injury and pain. BMC Public Health 2006;6:276.

41. Kröner-Herwig B, Morris L, Heinrich $M$, et al. Agreement of parents and children on characteristics of pediatric headache, other pains, somatic symptoms, and depressive symptoms in an epidemiologic study. Clin J Pain 2009;25:58-64. 